\title{
Clinical characteristics and manifestations in older patients with COVID-19
}

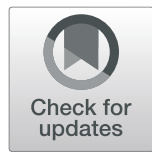

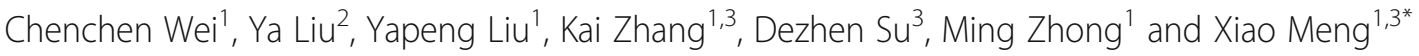

\begin{abstract}
Background: To investigate the clinical characteristics and manifestations of older patients with coronavirus disease 2019 (COVID-19).

Methods: In this retrospective study, 566 patients with confirmed COVID-19 were enrolled and the clinical characteristics, laboratory findings, complications and outcome data were collected and analyzed.

Results: Among the 566 patients (median age, 61.5 years) with COVID-19, 267 (47.2\%) patients were male and 307 (54.2\%) were elderly. Compared with younger patients, older patients had more underlying comorbidities and laboratory abnormalities. A higher rate of acute respiratory distress syndrome (ARDS), acute cardiac injury and heart failure was observed in the older group as compared with younger and middle-aged groups, particularly those oldest-old patients had more multi-organ damage. Older patients with COVID-19 were more likely to suffer from acute cardiac injury in cases with preexistenting cardiovascular diseases, while there was no difference among the three groups when patients had no history of cardiovascular diseases. Older patients presented more severe with the mortality of $18.6 \%$, which was higher than that in younger and middle-aged patients $(P<0.05)$. Multivariable analysis showed that age, lymphopenia, ARDS, acute cardiac injury, heart failure and skeletal muscle injury were associated with death in older patients, while glucocorticoids might be harmful.

Conclusions: Older patients, especially the oldest-old patients were more likely to exhibit significant systemic inflammation, pulmonary and extrapulmonary organ damage and a higher mortality. Advanced age, lymphopenia, ARDS, acute cardiac injury, heart failure and skeletal muscle injury were independent predictors of death in older patients with COVID-19 and glucocorticoids should be carefully administered in older patients.
\end{abstract}

Keywords: SARS-CoV-2, COVID-19, Older patients, Outcome

\footnotetext{
* Correspondence: mx81fly@sina.com

${ }^{1}$ The Key Laboratory of Cardiovascular Remodeling and Function Research, Chinese Ministry of Education, Chinese National Health Commission and Chinese Academy of Medical Sciences, The State and Shandong Province Joint Key Laboratory of Translational Cardiovascular Medicine, Department of Cardiology, Qilu Hospital, Cheeloo College of Medicine, Shandong University, Jinan 250012, China

${ }^{3}$ Department of Infectious Disease, Renmin Hospital of Wuhan University, Wuhan 430060, China

Full list of author information is available at the end of the article
}

(c) The Author(s). 2020 Open Access This article is licensed under a Creative Commons Attribution 4.0 International License, which permits use, sharing, adaptation, distribution and reproduction in any medium or format, as long as you give appropriate credit to the original author(s) and the source, provide a link to the Creative Commons licence, and indicate if changes were made. The images or other third party material in this article are included in the article's Creative Commons licence, unless indicated otherwise in a credit line to the material. If material is not included in the article's Creative Commons licence and your intended use is not permitted by statutory regulation or exceeds the permitted use, you will need to obtain permission directly from the copyright holder. To view a copy of this licence, visit http://creativecommons.org/licenses/by/4.0/ The Creative Commons Public Domain Dedication waiver (http://creativecommons.org/publicdomain/zero/1.0/) applies to the data made available in this article, unless otherwise stated in a credit line to the data. 


\section{Background}

COVID-19 caused by a novel coronavirus (SARS-CoV-2) has spread rapidly during the past several months. As a novel infectious disease, COVID-19 has the ability of human-to-human transmission and can lead to acute respiratory distress syndrome (ARDS), multiple organ dysfunction and even death [1]. As of April 30, more than three million confirmed cases and more than 200 thousand deaths worldwide were reported by the World Health Organization (WHO).

In China, there were 241 million elderly people aged over 60 years old, among whom more than 30 million were more than 80 years old [2]. The percentage of older adults ( $\geq 60$ years) was $17.3 \%$ of the total population. In addition, the number of the aged has dramatically augmented globally and subsequently, the frequency of age-associated diseases, particularly cardiovascular and cerebrovascular diseases, also increased significantly. Although the population is generally susceptible to SARSCoV-2, older people have higher morbidity and mortality than younger individuals, particularly those with serious underlying comorbidities [3]. The majority of patients infected by SARS-CoV-2 were over 50 years old, and nearly $80 \%$ of deaths occurred among individuals aged $\geq 60$ years [4].

Considering the complications and age-related vulnerability in older adults, it has been an enormous challenge to protect the function of multi-organ and decrease the mortality from SARS-CoV-2. Although many studies have focused on the clinical characteristics of COVID-19 patients, data about the damage of extrapulmonary organ due to SARS-CoV-2 among the elderly was still limited. Therefore, we aimed to compare the characteristics and manifestations of patients among different age and assess the extrapulmonary organ damage in older patients.

\section{Methods \\ Patients}

In this retrospective study, 566 patients with COVID-19 hospitalized from January 3, 2020 to March 16, 2020 at Renmin Hospital of Wuhan University were enrolled. All patients were defined the degree of COVID-19 as moderate or severe according to the Guidance for Corona Virus Disease 2019 (7th edition) issued by the China National Health Commission [5]. The study was approved by the Ethics Committees of Qilu Hospital of Shandong University and Renmin Hospital of Wuhan University.

\section{Data collection}

Epidemiological characteristics, laboratory findings, complications, treatment options and outcomes of enrolled patients were obtained from the electronic medical records. According to recent WHO definitions, patients were categorized into three groups: younger group (< 45 years), middle-aged group ( 45 to 59 years) and older group ( $\geq 60$ years). People aged 60 years were always still active, whereas individuals aged over 75 years might appear increasingly frail. Therefore, older patients were divided into two groups: the younger old (60 to 74 years) and the oldest-old ( $\geq 75$ years) groups in subgroup analysis.

The occurrence of organ damage was assessed by two independent physicians blinded to the study. ARDS was defined according to the Berlin definition [6]. Acute liver injury was defined as alanine aminotransferase (ALT) and/or aspartate aminotransferase (AST) over $3 \times$ the upper limit unit of normal (ULN), alkaline phosphatase (ALP), gamma-glutamyl transferase (GGT), and/or total bilirubin (TBIL) over $2 \times$ ULN. Acute kidney injury was identified on the basis of the highest serum creatinine level according to the kidney disease improving global outcomes classification [7]. Heart failure was defined by age-related amino-terminal pro-brain natriuretic peptide (NT-proBNP) cut-points $(450 \mathrm{pg} / \mathrm{mL}$ for patients $<50$ years, $900 \mathrm{pg} / \mathrm{mL}$ for patients between 50 and 75 years, and $1800 \mathrm{pg} / \mathrm{mL}$ for patients $>75$ years, respectively) and presence of associated symptoms, including dyspnea and edema. Acute cardiac injury was defined as the serum cardiac troponin I levels (cTnI) above the reference limit (>0.04 ng/ml). In addition, neurologic manifestations were also assessed, such as nervous system manifestations (dizziness, headache, impaired consciousness and acute cerebrovascular) and skeletal muscular injury manifestations, which indicated a patient had skeletal muscle pain and increased serum levels of creatine kinase.

\section{Statistical analysis}

Data were analyzed using IBM SPSS Statistics for Windows version 25.0 (SPSS Inc. Chicago, IL). The distribution of continuous variables was determined by the Shapiro-Wilk test. Non-normally distributed variables were expressed as median (IQR) and differences between groups were analyzed by the Mann-Whitney $U$ test or Kruskal-Wallis test followed by Dunn's post hoc. Categorical variables were compared using the $\chi^{2}$ test or Fisher's exact test, as appropriate. Prognostic factors of older patients were identified by univariate and multivariate logistic regression. Only those variables that were identified as significant in the univariate analysis were included in the multivariate analysis. All statistical tests were two-sided, and the differences were considered to be statistically significant at $P<0.05$.

\section{Results}

Demographic characteristics among 3 groups

Of 566 patients, the median age was 61.5 years and $47.2 \%$ of patients were male. Among the patients, 402 
(71.0\%) patients met the criteria for severe COVID-19 and $164(29.0 \%)$ patients were moderate cases. There were 102 (18.0\%), 157 (27.7\%) and 307 (54.2\%) patients in younger, middle-aged and older groups, with corresponding median age of 37, 54 and 69 years, respectively. Compared with younger and middle-aged groups, systolic blood pressure and the incidence of any coexisting medical condition were higher in the older group, like the occurrence of hypertension, diabetes and coronary artery disease (CAD). There was no difference of sex and symptoms among the three groups, including the neurologic manifestations (Table 1).

\section{Laboratory findings among 3 groups}

When compared with younger and middle-aged groups, older patients exhibited higher counts of neutrophils and serum levels of C-reactive protein (CRP), AST, $\mathrm{LDH}$, blood glucose, urea nitrogen and creatinine as well as lower numbers of lymphocytes, hemoglobin and platelet $(P<0.05)$. More severe lymphopenia occurred in older individuals where $101(32.9 \%)$ patients had lymphocyte counts below $0.8 \times 10^{9} / \mathrm{L}$, while only 13 $(12.7 \%)$ and $29(18.5 \%)$ in younger and middle-aged groups, respectively (Table 2 ).

Common complications were assessed and we observed that $28.7 \%$ of older patients suffered the ARDS, while the proportion of individuals exhibiting ARDS in younger and middle-aged patients were $14.7 \%$ and $22.3 \%$, respectively. Elevated cTnI and BNP levels were found in the older group when compared with those in younger and middle-aged groups, suggesting a higher rate of acute cardiac injury and heart failure. Surprisingly, older patients with preexisting cardiac comorbidity were more likely to suffered cardiac injury, while there was no difference of the incidence of acute cardiac injury among patients without cardiovascular diseases. On admission, there was decreased level of albumin in the older group with 18 (5.9\%) older patients developing hypoalbuminemia (albumin $<30 \mathrm{~g} / \mathrm{L}$ ), suggesting a poor nutrition status of older patients. There was no

Table 1 Demographic and baseline characteristics of COVID-19 patients among 3 groups

\begin{tabular}{|c|c|c|c|}
\hline & Younger $(n=102)$ & Middle-aged $(n=157)$ & Older $(n=307)$ \\
\hline Age (years) & $37.0(32.0-41.3)$ & $54.0(49.5-57.0)$ & $69.0(65.0-76.0)$ \\
\hline \multicolumn{4}{|l|}{ Sex } \\
\hline Male & $54(52.9 \%)$ & $60(38.2 \%)$ & $153(49.8 \%)$ \\
\hline Female & 48 (47.1\%) & $97(61.8 \%)$ & $154(50.2 \%)$ \\
\hline \multicolumn{4}{|l|}{ Typical symptoms } \\
\hline Fever & $71(69.6 \%)$ & $126(80.3 \%)$ & $248(80.8 \%)$ \\
\hline Dry cough & $63(61.8 \%)$ & $108(68.8 \%)$ & $183(59.6 \%)$ \\
\hline Fatigue & 38 (37.3\%) & 76 (48.4\%) & 144 (46.9\%) \\
\hline Dyspnea & $12(11.8 \%)$ & $26(16.6 \%)$ & $41(13.4 \%)$ \\
\hline \multicolumn{4}{|l|}{ Neurological symptoms } \\
\hline Dizziness & 3/102 (2.9\%) & 9/156 (5.8\%) & 16/302 (5.3\%) \\
\hline Headache & $5 / 102(4.9 \%)$ & 13/156 (8.3\%) & 10/302 (3.3\%) \\
\hline Impaired consciousness & $0(0.0 \%)$ & $0(0.0 \%)$ & $3(1.0 \%)$ \\
\hline \multicolumn{4}{|l|}{ Comorbidity } \\
\hline Any & $18(17.6 \%)$ & $66(42.0 \%)^{*}$ & $222(72.3 \%)^{* \#}$ \\
\hline Hypertension & $6(5.9 \%)$ & $52(33.1 \%)^{*}$ & $158(51.5 \%)^{* \#}$ \\
\hline Diabetes & $3(2.9 \%)$ & $19(12.1 \%)^{*}$ & $52(16.9 \%)^{*}$ \\
\hline CAD & $0(0.0 \%)$ & $8(5.1 \%)$ & $50(16.3 \%)^{* \#}$ \\
\hline Cerebral infarction & $0(0.0 \%)$ & $1(0.6 \%)$ & $21(6.8 \%)^{*}$ \\
\hline Cancer & $1(1.0 \%)$ & $2(1.3 \%)$ & $9(2.9 \%)$ \\
\hline CKD & $2(2.0 \%)$ & $1(0.6 \%)$ & $7(2.3 \%)$ \\
\hline COPD & $0(0.0 \%)$ & $1(0.6 \%)$ & $7(2.3 \%)$ \\
\hline SBP (mmHg) & $122.0(116.0-130.0)$ & $129.0(120.0-140.0)^{*}$ & $134.0(121.0-148.0)^{*}$ \\
\hline $\mathrm{DBP}(\mathrm{mmHg})$ & 78.0 (70.0-85.0) & $80.0(70.0-87.5)$ & $80.0(70.0-87.0)$ \\
\hline Heart rate (bpm) & $85.0(76.0-98.0)$ & $86.0(77.5-96.0)$ & $85.0(77.0-98.0)$ \\
\hline
\end{tabular}

Data were presented as $\mathrm{n}(\%)$ or median (IQR). ${ }^{*} P<0.05$ vs younger group; ${ }^{\#} P<0.05$ vs middle-aged group. $C A D$ coronary artery disease, $C K D$ chronic kidney disease, COPD chronic obstructive pulmonary disease, SBP systolic blood pressure, DBP diastolic blood pressure 
Table 2 The laboratory findings, complications, treatment and clinical outcome of patients with COVID-19 among 3 groups

\begin{tabular}{|c|c|c|c|}
\hline & Younger $(n=102)$ & Middle-aged $(n=157)$ & Older $(n=307)$ \\
\hline White blood cells $\left(10^{9} / \mathrm{L}\right)$ & $5.57(4.16-7.18)$ & $5.37(4.28-7.07)$ & $5.73(4.53-7.56)$ \\
\hline Neutrophils $\left(10^{9} / \mathrm{L}\right)$ & $2.93(2.11-4.66)$ & $3.14(2.55-4.59)$ & $3.87(2.73-5.56)^{* \#}$ \\
\hline Lymphocytes $\left(10^{9} / \mathrm{L}\right)$ & $1.52(1.09-2.02)$ & $1.31(0.90-1.73)$ & $1.01(0.68-1.57)^{* \#}$ \\
\hline$<0.8$ & $13(12.7 \%)$ & $29(18.5 \%)$ & $101(32.9 \%)^{* \#}$ \\
\hline Hemoglobin (g/L) & $133.0(122.8-145.0)$ & $125.0(116.5-135.5)^{*}$ & $121.0(111.0-132.0)^{* \#}$ \\
\hline Platelet $\left(10^{9} / \mathrm{L}\right)$ & $220.5(177.3-272.3)$ & $231.0(178.0-295.5)$ & $208.0(155.0-261.0)^{\#}$ \\
\hline$<100$ & $0(0.0 \%)$ & $2(1.3 \%)$ & $19(6.2 \%)^{* \# \#}$ \\
\hline CRP (mg/L) & $2.53(0.50-11.88)$ & $5.60(0.71-37.40)$ & $27.70(2.64-72.85)^{* \#}$ \\
\hline $\operatorname{ALT}(U / L)$ & $26.0(17.8-48.0)$ & $27.0(18.0-51.0)$ & $23.0(16.0-36.0)^{\#}$ \\
\hline AST (U/L) & $23.0(17.0-33.3)$ & $25.0(19.0-37.0)$ & $27.0(19.0-39.0)^{*}$ \\
\hline ALP (U/L) & $57.0(45.0-69.3)$ & $64.5(52.0-81.3)^{*}$ & $66.0(55.0-81.0)^{*}$ \\
\hline GGT (U/L) & $23.0(15.0-39.3)$ & $29.5(18.0-51.0)$ & $27.0(17.0-47.0)$ \\
\hline Total bilirubin $(\mu \mathrm{mol} / \mathrm{L})$ & $10.1(7.2-13.0)$ & $10.2(7.5-13.7)$ & $11.1(8.4-15.2)^{* \#}$ \\
\hline Albumin (g/L) & $41.5(38.4-44.7)$ & $39.4(36.6-42.1)^{*}$ & $36.6(33.1-39.3)^{* \#}$ \\
\hline$<30$ & $0(0.0 \%)$ & $0(0.0 \%)$ & $18(5.9 \%)^{* \#}$ \\
\hline Urea nitrogen (mmol/L) & $4.11(3.10-5.42)$ & $4.53(3.40-5.61)$ & $5.40(4.28-7.41)^{* \#}$ \\
\hline Creatinine $(\mu \mathrm{mol} / \mathrm{L})$ & $61.0(48.8-72.0)$ & $55.0(46.5-67.5)$ & $63.0(52.0-75.0)^{\#}$ \\
\hline Blood glucose (mmol/L) & $4.99(4.59-5.87)$ & $5.36(4.83-6.76)^{*}$ & $5.80(5.04-7.43)^{* \#}$ \\
\hline Creatine kinase (U/L) & $61.0(44.0-108.0)$ & $56.0(35.0-82.5)$ & $60.0(42.0-94.5)$ \\
\hline LDH (U/L) & $189.0(164.8-298.5)$ & $227.0(187.0-281.0)$ & $265.0(210.0-363.0)^{* \#}$ \\
\hline CK-MB (ng/mL) & $0.64(0.44-0.88)$ & $0.75(0.54-1.05)$ & $1.27(0.90-2.25)^{* \#}$ \\
\hline $\mathrm{cTnl}(\mathrm{ng} / \mathrm{mL})$ & $0.006(0.006-0.006)$ & $0.006(0.006-0.006)$ & $0.008(0.006-0.025)^{* \#}$ \\
\hline \multicolumn{4}{|l|}{ Complications } \\
\hline ARDS & $15(14.7 \%)$ & $35(22.3 \%)$ & $88(28.7 \%)^{*}$ \\
\hline Acute cardiac injury & 4/91 (4.4\%) & $5 / 154(3.2 \%)$ & $66 / 306(21.6 \%)^{* \#}$ \\
\hline With history of cardiovascular disease & $0 / 5(0.0 \%)$ & $0 / 53(0.0 \%)$ & $56 / 178(31.5 \%)^{\#}$ \\
\hline Without history of cardiovascular disease & $4 / 86(4.7 \%)$ & $5 / 101(5.0 \%)$ & $10 / 128(7.8 \%)$ \\
\hline Heart failure (elevated BNP) & $1 / 72(1.4 \%)$ & 5/132 (3.8\%) & $39 / 269(14.5 \%)^{* \#}$ \\
\hline Novel or worsening arrhythmia & $21(20.6 \%)$ & $26(16.6 \%)$ & $71(23.1 \%)$ \\
\hline Acute liver injury & $9(8.8 \%)$ & $11(7.0 \%)$ & $35(11.4 \%)$ \\
\hline Acute kidney injury & $2(2.0 \%)$ & $1(0.6 \%)$ & $13(4.2 \%)$ \\
\hline Skeletal muscle injury & 9/102 (8.8\%) & $8 / 150(5.3 \%)$ & 20/285 (7.0\%) \\
\hline \multicolumn{4}{|l|}{ Treatment } \\
\hline Antiviral therapy & $97(95.1 \%)$ & $150(95.5 \%)$ & $295(96.1 \%)$ \\
\hline Antibiotic therapy & $66(64.7 \%)$ & $114(72.6 \%)$ & $230(74.9 \%)$ \\
\hline Glucocorticoids & $27(26.5 \%)$ & $42(26.8 \%)$ & $127(41.4 \%)^{* \#}$ \\
\hline \multicolumn{4}{|l|}{ Oxygen support } \\
\hline Nasal cannula & $71(69.6 \%)$ & $111(70.7 \%)$ & $220(71.7 \%)$ \\
\hline Non-invasive ventilation (ie, face mask) & $9(8.8 \%)$ & $25(15.9 \%)$ & $65(21.2 \%)^{*}$ \\
\hline Invasive mechanical ventilation & $1(1.0 \%)$ & $4(2.5 \%)$ & $12(3.9 \%)$ \\
\hline Severe & $49(48.0 \%)$ & $99(63.1 \%)^{*}$ & $254(82.7 \%)^{* \#}$ \\
\hline \multicolumn{4}{|l|}{ Clinical outcome } \\
\hline Discharge & $100(98.0 \%)$ & $150(95.5 \%)$ & $250(81.4 \%)^{* \#}$ \\
\hline Death & $2(2.0 \%)$ & $7(4.5 \%)$ & $57(18.6 \%)^{* \#}$ \\
\hline
\end{tabular}

${ }^{*} P<0.05$ vs younger group; ${ }^{\# P}<0.05$ vs middle-aged group. $C R P$ C-reactive protein, $A L T$ alanine aminotransferase, $A S T$ aspartate aminotransferase, $A L P$ alkaline phosphatase, GGT gamma-glutamyl transferase, $L D H$ lactate dehydrogenase, CK-MB creatine kinase-myocardial isoenzyme, $c T n /$ cardiac troponin I ARDS acute respiratory distress syndrome 
difference of novel or worsening arrhythmia, acute liver injury, acute kidney injury and skeletal muscle injury among the three groups (Table 2).

Among the total of 566 patients, $95.8 \%$ of individuals received antiviral agents (including arbidol, ribavirin, oseltamivir and ganciclovir) and more than half of patients received antibacterial therapy. $34.6 \%$ of patients received glucocorticoids therapy (methylprednisolone, 40-80 mg/day for 5-7 days). More glucocorticoids were used in older patients $(41.4 \%)$ than younger and middleaged patients $(26.5 \%$ or $26.8 \%, P<0.05) .82 .7 \%$ of older patients were severe and $18.6 \%$ of them died eventually, which was higher than that in younger and middle-aged patients $(P<0.05)$. There was no significant difference of treatment and mortality between younger and middleaged groups (Table 2).

\section{The subgroup analysis of older patients}

In subgroup analysis, older patients were further divided into two groups: younger old and oldest-old groups. Among the 307 older patients, there were 216 (70.4\%) younger old patients and 91 (29.6\%) oldest-old patients. The incidence of hypertension and CAD was more frequent in oldest-old patients. Compared with the younger old, oldest-old patients had higher counts of neutrophils and serum levels of CRP, AST, urea nitrogen, creatinine, LDH, CK-MB and cTnI, while lower counts of lymphocytes and platelet and serum albumin levels $(P<0.05)$. Oldest-old patients exhibited higher incidence of extrapulmonary organ damage, including acute cardiac injury, heart failure, skeletal muscle injury and kidney injury than those in younger old patients $(P<0.05)$. Importantly, the mortality of the oldest-old patients was much higher than younger old patients $(P<0.001$, Table 3$)$.

In addition, the older patients were divided into two sub-groups: survivors $(n=250)$ and non-survivors $(n=$ 57). Compared with survivors, non-survivors were older, and had higher comorbidity rates including hypertension and CAD $(P<0.05)$. Non-survivors were more likely to suffer ARDS (68.4\% vs. $19.6 \%)$, acute myocardial injury (71.9\% vs. $10.0 \%)$, heart failure $(43.4 \%$ vs. $7.4 \%)$, skeletal muscle injury $(26.7 \%$ vs. $3.3 \%)$ and acute kidney injury (10.5\% vs. $2.8 \%$, all $P<0.05)$ as compared with survivors. Among all 57 non-survivors, 53 patients (93.0\%) had ARDS and/or cardiac complications (Table S1).

\section{The predictors for the prognosis of elderly patients}

Univariate and multivariable logistic regression analyses were performed and we found that age was an independent risk factor for the prognosis of older COVID-19 patients, and the risk of death increased by $8.5 \%$ per year approximately in elderly population. ARDS, acute cardiac injury, heart failure, skeletal muscle injury and lymphopenia were all independent risk factors associated with death. Disappointedly, glucocorticoids were associated with an increased mortality in older patients with COVID-19 (OR: 3.990; 95\%CI: 1.364-11.668; $P=0.011$, Table 4).

\section{Discussion}

SARS-CoV-2 was more likely to affect older patients, particularly those with comorbidities [3]. To our best knowledge, this is the first report to systematically describe the extrapulmonary organ damage caused by SARS-CoV-2 in older patients. In this study, we showed that older patients with COVID-19 exhibited more coexisting diseases, ARDS and extrapulmonary organ damage, which were associated with a higher mortality. Moreover, oldest-old patients showed higher incidence of multi-organ dysfunction and mortality.

Aging is a complex and multifactorial process. Frailty, the common problem of aging population, is a nonspecific state of vulnerability to poor resolution of homeostasis following a stress [8]. The prevalence of frailty increased with age, the elderly older than age 65 accounted for $22.4 \%$, while $43.7 \%$ for those over 85 years old [9]. Increasing frailty with age was associated with increased risk of infection and mortality [4]. In this study, $41.7 \%$ of patients were aged over 65 years and $3.2 \%$ was 85 or even older. In addition, many older patients with COVID-19 had one or more comorbities, making them more susceptible to SARS-CoV-2 infection and had greater severe illness. In this study, $72.3 \%$ of older patients had at least one coexisting illness.

Compared with SARS, COVID-19 had a lower case fatality. It has been reported that the over-all mortality was $1.4 \%$ [10]. Although most younger people infected by SARS-CoV-2 were asymptomatic or mildly ill, the elderly exhibited more severe symptoms and higher mortality. It is estimated that the mortality was $1.4 \%$ in the elderly less than 60 years old while increased by $4.5 \%$ in older individuals over 60 years old and by $14.8 \%$ in patients aged 80 or older [11]. In this study, the condition of older patients was more serious and the mortality was $18.6 \%$, which was significantly higher than that of younger and middle-aged patients.

SARS-CoV-2 infection is able to result in clusters of severe pneumonia and even ARDS, which is the leading cause of death in patients with COVID-19. In one study enrolling 201 COVID-19 patients, $41.8 \%$ of patients developed ARDS and $52.4 \%$ of them died eventually [12]. In another study by Lian J et al., $16.9 \%$ of older patients ( $\geq 60$ years) developed ARDS, which only accounted for $5.37 \%$ in younger patients ( $<60$ years) [13]. They argued that older age was associated with greater risk of development of ARDS and death [13]. In this study, older patients exhibited higher counts of neutrophils and CRP levels, suggesting an augmented inflammatory response. 
Table 3 The laboratory findings, complications, treatment and clinical outcome in the older patients

\begin{tabular}{|c|c|c|c|}
\hline & Younger old $(n=216)$ & Oldest-old $(n=91)$ & $P$ \\
\hline Age (years) & $66.0(63.0-69.0)$ & $79.0(76.0-82.0)$ & $<0.001$ \\
\hline Male & $96(44.4 \%)$ & $57(62.6 \%)$ & 0.004 \\
\hline \multicolumn{4}{|l|}{ Comorbidity } \\
\hline Any & $143(66.2 \%)$ & 79 (86.8\%) & $<0.001$ \\
\hline Hypertension & $96(44.4 \%)$ & $62(68.1 \%)$ & $<0.001$ \\
\hline Diabetes & $37(17.1 \%)$ & $15(16.5 \%)$ & 0.890 \\
\hline CAD & $27(12.5 \%)$ & $23(25.3 \%)$ & 0.006 \\
\hline Cerebral infarction & $8(3.7 \%)$ & $13(14.3 \%)$ & 0.001 \\
\hline Cancer & $6(2.8 \%)$ & $3(3.3 \%)$ & 1.000 \\
\hline CKD & $3(1.4 \%)$ & $4(4.4 \%)$ & 0.233 \\
\hline COPD & $3(1.4 \%)$ & $4(4.4 \%)$ & 0.233 \\
\hline \multicolumn{4}{|l|}{ Laboratory findings } \\
\hline White blood cells $\left(10^{9} / \mathrm{L}\right)$ & $5.72(4.34-7.39)$ & $5.96(4.74-8.12)$ & 0.155 \\
\hline Neutrophils $\left(10^{9} / \mathrm{L}\right)$ & $3.70(2.54-5.47)$ & $4.30(3.37-6.54)$ & 0.006 \\
\hline Lymphocytes $\left(10^{9} / L\right)$ & $1.18(0.73-1.68)$ & $0.85(0.59-1.29)$ & $<0.001$ \\
\hline$<0.8$ & $58(26.9 \%)$ & $43(47.3 \%)$ & 0.001 \\
\hline Hemoglobin (g/L) & $121.0(112.0-131.0)$ & $121.0(109.0-133.0)$ & 0.660 \\
\hline Platelet $\left(10^{9} / \mathrm{L}\right)$ & $213.0(165.3-269.5)$ & $197.0(134.0-242.0)$ & 0.011 \\
\hline$<100$ & $10(4.6 \%)$ & $9(9.9 \%)$ & 0.081 \\
\hline CRP (mg/L) & 18.90 (1.37-73.09) & 53.55 (12.28-73.03) & 0.001 \\
\hline $\mathrm{ALT}(\mathrm{U} / \mathrm{L})$ & $24.0(16.0-35.8)$ & $23.0(16.0-39.0)$ & 0.829 \\
\hline AST (U/L) & $25.0(18.0-35.8)$ & $30.0(21.0-48.0)$ & 0.002 \\
\hline Albumin $(g / L)$ & $37.1(33.6-40.0)$ & $35.0(32.0-37.7)$ & $<0.001$ \\
\hline$<30$ & $11(5.1 \%)$ & $7(7.7 \%)$ & 0.376 \\
\hline Urea nitrogen (mmol/L) & $5.10(4.00-6.51)$ & $7.70(4.80-11.31)$ & $<0.001$ \\
\hline Creatinine $(\mu \mathrm{mol} / \mathrm{L})$ & $60.0(50.0-70.0)$ & $68.0(57.0-100.0)$ & $<0.001$ \\
\hline Blood glucose (mmol/L) & $5.80(5.06-7.74)$ & $5.79(4.90-7.01)$ & 0.658 \\
\hline Creatine kinase $(U / L)$ & $59.0(42.0-86.5)$ & $62.0(42.5-150.0)$ & 0.103 \\
\hline $\mathrm{LDH}(\mathrm{U} / \mathrm{L})$ & $252.0(200.0-346.0)$ & $289.0(230.0-452.0)$ & 0.001 \\
\hline CK-MB (ng/mL) & $1.12(0.83-1.63)$ & $2.27(1.32-4.43)$ & $<0.001$ \\
\hline cTnl (ng/mL) & $0.006(0.006-0.014)$ & $0.027(0.010-0.193)$ & $<0.001$ \\
\hline \multicolumn{4}{|l|}{ Complications } \\
\hline ARDS & $56(25.9 \%)$ & $32(35.2 \%)$ & 0.102 \\
\hline Acute cardiac injury & $23 / 215(10.7 \%)$ & 43/91 (47.3\%) & $<0.001$ \\
\hline With history of cardiovascular disease & 19/108 (17.6\%) & $37 / 70(52.9 \%)$ & $<0.001$ \\
\hline Without history of cardiovascular disease & $4 / 107(3.7 \%)$ & 6/21 (28.6\%) & 0.001 \\
\hline Heart failure (elevated BNP) & 21/185 (11.4\%) & 18/84 (21.4\%) & 0.030 \\
\hline New or worsening arrhythmia & $54(25.0 \%)$ & $17(18.7 \%)$ & 0.230 \\
\hline Acute liver injury & $20(9.3 \%)$ & $15(16.5 \%)$ & 0.069 \\
\hline Acute kidney injury & $4(1.9 \%)$ & $9(9.9 \%)$ & 0.004 \\
\hline Skeletal muscle injury & 9/204 (4.4\%) & 11/81 (13.6\%) & 0.006 \\
\hline \multicolumn{4}{|l|}{ Clinical outcome } \\
\hline Discharge & $191(88.4 \%)$ & $59(64.8 \%)$ & $<0.001$ \\
\hline Death & $25(11.6 \%)$ & $32(35.2 \%)$ & \\
\hline
\end{tabular}


Table 4 Univariate and multivariate regression analysis for predicting the risk of death in older patients with COVID-19

\begin{tabular}{|c|c|c|c|c|}
\hline & \multicolumn{2}{|l|}{ Univariate } & \multicolumn{2}{|l|}{ Multivariate } \\
\hline & OR $(95 \% \mathrm{Cl})$ & $P$ & OR $(95 \% \mathrm{Cl})$ & $P$ \\
\hline Age (years) & $1.111(1.069-1.155)$ & 0.000 & $1.085(1.017-1.158)$ & 0.014 \\
\hline History of cardiovascular disease & $3.299(1.665-6.535)$ & 0.001 & & \\
\hline ARDS & $8.888(4.687-16.853)$ & 0.000 & $8.576(3.084-23.850)$ & 0.000 \\
\hline Acute cardiac injury & $22.960(11.284-46.717)$ & 0.000 & $3.690(1.233-11.042)$ & 0.020 \\
\hline Heart failure & $9.583(4.552-20.178)$ & 0.000 & $4.782(1.543-14.817)$ & 0.007 \\
\hline New or worsening arrhythmia & $1.384(0.722-2.652)$ & 0.328 & & \\
\hline Acute liver injury & $1.915(0.862-4.253)$ & 0.111 & & \\
\hline Acute kidney injury & $4.084(1.317-12.661)$ & 0.015 & & \\
\hline Skeletal muscle injury & $10.545(4.013-27.709)$ & 0.000 & $7.330(1.453-36.977)$ & 0.016 \\
\hline Leukocytosis & $10.635(4.897-23.094)$ & 0.000 & & \\
\hline Lymphopenia & $4.435(2.427-8.105)$ & 0.000 & $2.793(1.030-7.578)$ & 0.044 \\
\hline Hypoalbuminemia & $3.042(1.124-8.231)$ & 0.028 & & \\
\hline Antiviral therapy & $1.146(0.244-5.378)$ & 0.863 & & \\
\hline Antibiotic therapy & $7.714(2.338-25.450)$ & 0.001 & & \\
\hline Glucocorticoids & $3.989(2.155-7.384)$ & 0.000 & $3.990(1.364-11.668)$ & 0.011 \\
\hline
\end{tabular}

Meanwhile, older patients showed a higher incidence of ARDS, which was an independent risk factor for death.

Some COVID-19 patients without common symptom (fever or cough) came to hospital with only cardiovascular manifestations as their presenting symptoms. Cardiac injury is also one of essential causes of death in patients with COVID-19. Patients with cardiovascular comorbidities were more likely to develop cardiac complications and Ruan Q et al. reported that $40 \%$ of deaths were associated with circulatory failure due to cardiac injury [14]. In this study, older patients had increased incidence of acute cardiac injury and heart failure, which were independently associated with poor outcome in elderly patients with COVID-19. Importantly, acute cardiac injury could be developed no matter whether there was cardiovascular disease previously.

Nutritional status of the host exerts a crucial role in the defense against infection, and individuals with nutritional deficiency are more susceptible to a series of infectious diseases which can lead to a detrimental consequence $[15,16]$. Malnutrition has been considered as an independent risk factor for increased complications and higher mortality in hospitalized patients [17]. The basic nutritional status of older patients with chronic diseases is always poor, which makes them tend to be critically ill after infection [18]. In this study, the older patients were more likely to develop hypoalbuminemia and decreased hemoglobin, suggesting they were under a poor nutrition state, which might be a cause of higher mortality in older patients.

Recently, a descriptive study indicated $36.4 \%$ of patients with COVID-19 had nervous system manifestations [19]. However, we did not find any difference of nervous system manifestations among the three groups. And, we also did not find any difference of acute liver or kidney injury. However, oldest-old patients showed higher skeletal muscle injury and acute kidney injury.

Immune system exerts a central role in host-viral interactions and aging has the ability to induce a series of changes that affect the immune system. Immunosenescence is an age-related process that affects both innate and adaptive immunity, increasing the vulnerability and mortality of elderly to infectious diseases [20]. Immune organs such as thymus and lymph nodes atrophy gradually with age, and aging has a profound impact on the phenotype and functions of various immune cells [20, 21]. Many patients with COVID-19 exhibited lymphopenia, which was more prominent in those severe patients $[10,22]$. In our study, persistent and more severe lymphopenia was observed in older patients, $32.9 \%$ of whom had lymphocyte counts below $0.8 \times 10^{9} / \mathrm{L}$, which suggested a damaged immune system. The damaged immune function, caused by immunosenescence and preceding coronavirus infection, increased the susceptibility to secondary bacterial pneumonia.

To date, no vaccine or specific therapeutic drug for COVID-19 has been approved. The treatment of elderly patients faces special challenges due to complications and general age-related vulnerability. Although glucocorticoids treatment was likely required in patients with coronavirus pneumonia, their efficacy remains controversial. A meta-analysis enrolled 5270 patients showed that corticosteroid use may increase mortality and 
serious adverse reactions in patients with COVID-19 [23]. However, in RECOVERY trial, dexamethasone (6 mg once daily for up to 10 days) treatment reduced 28-day mortality among those COVID-19 patients receiving invasive mechanical ventilation or oxygen at randomization but not among patients receiving no respiratory support [24]. Among 2104 patients, $54 \%$ of patients with dexamethasone therapy were younger than 70 years [24]. Older patients always have more comorbidities and they are not sensitive to many drugs and have more adverse effects of prescription drugs than younger patients. Therefore, glucocorticoids use may present a different effect in older patients with COVID-19. In our study, we focused on the effect of glucocorticoids in the older patients with COVID-19 and found glucocorticoids use were associated with an increased mortality in older patients. Maybe the different results were due to the heterogeneity in the choice, dosage and timing of steroids therapy, different crowds, medical conditions and disease severity. Therefore, caution in glucocorticoids use in older patients is advisable.

There were several limitations in this study. First of all, this was a single-center, retrospective analysis and a number of confounding factors may influence the clinical outcomes. Secondly, as one of the designated hospitals for severe COVID-19, most of patients enrolled were severe cases, which might be different from the whole infected population.

\section{Conclusions}

As the host receptor of SARS-CoV-2, ACE2 exists in multiple human organs, including lung, heart, nervous system and skeletal muscles, which may explain why SARS-CoV-2 is able to lead to multiple organs damage. Older patients, especially the oldest-old patients are more likely to exhibit significant systemic inflammation, pulmonary and extrapulmonary organ damage and a higher mortality. This may be due to more comorbidities, immunosenescence, decreased immune function, poor nutrition state and increased frailty in older patients. Age, ARDS, acute cardiac injury, heart failure, skeletal muscle injury and lymphopenia are associated with the mortality and glucocorticoids may be harmful for older patients with COVID-19. Considering the higher severity and lethality in older patients with COVID-19, physicians should closely monitor and prevent the possible organ damage to improve their survival and reduce the mortality.

\section{Supplementary information}

Supplementary information accompanies this paper at https://doi.org/10. 1186/s12877-020-01811-5.

Additional file 1.

\section{Abbreviations}

ALP: Alkaline phosphatase; ALT: Alanine aminotransferase; ARDS: Acute respiratory distress syndrome; AST: Aspartate aminotransferase;

CAD: Coronary artery disease; CK-MB: Creatine kinase-myocardial isoenzyme; COVID-19: Coronavirus disease 2019; CRP: C-reactive protein; cTnl: Cardiac troponin I; GGT: Gamma-glutamyl transferase; LDH: Lactate dehydrogenase; NT-proBNP: Amino-terminal pro-brain natriuretic peptide; TBIL: Total bilirubin

\section{Acknowledgments}

We thank all patients involved in the study.

\section{Authors' contributions}

$Y L, K Z$, DS and XM collected the epidemiological and clinical data and performed the statistical data. CW and $\mathrm{YL}$ analyzed the data and drafted the manuscript. $\mathrm{MZ}$ and $\mathrm{XM}$ designed the study. XM was responsible for summarizing all data. All authors have read and approved the manuscript.

\section{Funding}

The study was supported by the grants of the National Natural Science Foundation of China (No. 81970319). The funders had no role in the design of the study, collection, analysis, interpretation of data, and in writing the manuscript.

\section{Availability of data and materials}

The datasets used during the current study are available from the corresponding author on reasonable request.

Ethics approval and consent to participate

The study was approved by the Ethics Committees of Qilu Hospital of Shandong University and Renmin Hospital of Wuhan University. The informed consent was waived for its retrospective nature.

Consent for publication

Not applicable.

\section{Competing interests}

We declare no competing interests.

\section{Author details}

'The Key Laboratory of Cardiovascular Remodeling and Function Research, Chinese Ministry of Education, Chinese National Health Commission and Chinese Academy of Medical Sciences, The State and Shandong Province Joint Key Laboratory of Translational Cardiovascular Medicine, Department of Cardiology, Qilu Hospital, Cheeloo College of Medicine, Shandong University, Jinan 250012, China. ${ }^{2}$ Department of Gastroenterology, Renmin Hospital of Wuhan University, Wuhan 430060, China. ${ }^{3}$ Department of Infectious Disease, Renmin Hospital of Wuhan University, Wuhan 430060, China.

Received: 10 May 2020 Accepted: 30 September 2020

Published online: 08 October 2020

\section{References}

1. Jiang F, Deng L, Zhang L, Cai Y, Cheung CW, Xia Z. Review of the clinical characteristics of coronavirus disease 2019 (COVID-19). J Gen Intern Med. 2020;35(5):1545-9.

2. Liu YL. China's aging population: from a global perspective. Beijing: Social sciences academic press; 2019. (in Chinese).

3. Li Q, Guan X, Wu P, Wang X, Zhou L, Tong Y, et al. Early transmission dynamics in Wuhan, China, of novel coronavirus-infected pneumonia. N Engl J Med. 2020;382(13):1199-207.

4. Zhavoronkov A. Geroprotective and senoremediative strategies to reduce the comorbidity, infection rates, severity, and lethality in gerophilic and gerolavic infections. Aging (Albany NY). 2020;12(8):6492-510.

5. Interim guidance for novel coronavirus pneumonia (trial implementation of seventh edition). National Health Commision of the People's Republic of China; 2020. http://www.nhc.gov.cn/yzygj/s7653p/202003/46c9294a7dfe4 cef80dc7f5912eb1989 shtml. Accessed 13 Apr 2020.

6. ARDS Definition Task Force, Ranieri VM, Rubenfeld GD, Thompson BT,

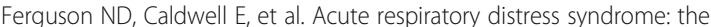
Berlin Definition. JAMA. 2012;307(23):2526-33. 
7. Khwaja A. KDIGO clinical practice guidelines for acute kidney injury. Nephron Clin Pract. 2012;120(4):c179-84.

8. Clegg A, Young J, lliffe S, Rikkert MO, Rockwood K. Frailty in elderly people. Lancet. 2013;381(9868):752-62.

9. Rockwood K, Song X, Mitnitski A. Changes in relative fitness and frailty across the adult lifespan: evidence from the Canadian National Population Health Survey. CMAJ. 2011;183(8):E487-94.

10. Guan WJ, Ni ZY, Hu Y, Liang WH, Ou CQ, He JX, et al. Clinical characteristics of coronavirus disease 2019 in China. N Engl J Med. 2020;382(18):1708-20.

11. Verity R, Okell LC, Dorigatti I, Winskill P, Whittaker C, Imai N, et al. Estimates of the severity of coronavirus disease 2019: a model-based analysis. Lancet Infect Dis. 2020;20(6):669-77.

12. Wu C, Chen X, Cai Y, Xia J, Zhou X, Xu S, et al. Risk factors associated with acute respiratory distress syndrome and death in patients with coronavirus disease 2019 pneumonia in Wuhan, China. JAMA Intern Med. 2020;180(7): 934-43.

13. Lian J, Jin X, Hao S, Cai H, Zhang S, Zheng L, et al. Analysis of epidemiological and clinical features in older patients with coronavirus disease 2019 (COVID-19) outside Wuhan. Clin Infect Dis. 2020;71(15):740-7.

14. Ruan Q, Yang K, Wang W, Jiang L, Song J. Clinical predictors of mortality due to COVID-19 based on an analysis of data of 150 patients from Wuhan, China. Intensive Care Med. 2020:46(5):846-8.

15. Zhang L, Liu Y. Potential interventions for novel coronavirus in China: a systematic review. J Med Virol. 2020;92(5):479-90.

16. Guillin OM, Vindry C, Ohlmann T, Chavatte L. Selenium, selenoproteins and viral infection. Nutrients. 2019:11(9):2101.

17. Correia MI, Waitzberg DL. The impact of malnutrition on morbidity, mortality, length of hospital stay and costs evaluated through a multivariate model analysis. Clin Nutr. 2003;22(3):235-9.

18. Chen N, Zhou M, Dong X, Qu J, Gong F, Han Y, et al. Epidemiological and clinical characteristics of 99 cases of 2019 novel coronavirus pneumonia in Wuhan, China: a descriptive study. Lancet. 2020;395(10223):507-13.

19. Mao L, Jin H, Wang M, Hu Y, Chen S, He Q, et al. Neurologic manifestations of hospitalized patients with coronavirus disease 2019 in Wuhan, China. JAMA Neurol. 2020;77(6):683-90.

20. Nikolich-Žugich J. The twilight of immunity: emerging concepts in aging of the immune system. Nat Immunol. 2018:19(1):10-9.

21. Solana R, Tarazona R, Gayoso I, Lesur O, Dupuis G, Fulop T. Innate immunosenescence: effect of aging on cells and receptors of the innate immune system in humans. Semin Immunol. 2012;24(5):331-41.

22. Liu K, Chen Y, Lin R, Han K. Clinical features of COVID-19 in elderly patients: a comparison with young and middle-aged patients. J Infect. 2020;80(6): e14-8.

23. Yang Z, Liu J, Zhou Y, Zhao X, Zhao Q, Liu J. The effect of corticosteroid treatment on patients with coronavirus infection: a systematic review and meta-analysis. J Infect. 2020;81(1):e13-20.

24. RECOVERY Collaborative Group, Horby P, Lim WS, Emberson JR, Mafham M, Bell JL, et al. Dexamethasone in hospitalized patients with covid-19preliminary report. N Engl J Med. 2020. https://doi.org/10.1056/ NEJMoa2021436

\section{Publisher's Note}

Springer Nature remains neutral with regard to jurisdictional claims in published maps and institutional affiliations.

Ready to submit your research? Choose BMC and benefit from:

- fast, convenient online submission

- thorough peer review by experienced researchers in your field

- rapid publication on acceptance

- support for research data, including large and complex data types

- gold Open Access which fosters wider collaboration and increased citations

- maximum visibility for your research: over $100 \mathrm{M}$ website views per year

At $\mathrm{BMC}$, research is always in progress.

Learn more biomedcentral.com/submissions 